\title{
Occult Expression of Non Syndromic Sex Cord Tumor with Annular Tubules in Ovary with Coexistent Cervical Fibroid
}

\author{
Poonam Rani', Khushboo Dewan ${ }^{2}$, Arti Khatri ${ }^{3}$, Karsing Patiri ${ }^{4}$, AKMandal $^{5}$ \\ ${ }^{1}$ Tutor, ${ }^{2}$ Assistant Professor, ${ }^{3}$ Assistant Professor, ${ }^{4}$ Assistant Professor, ${ }^{5}$ Professor, Department of Pathology, Dr. Baba Saheb \\ Ambedkar Medical College and Hospital, Rohini, Delhi, India.
}

DOI: https://doi.org/10.24321/2454.8642.202001

\section{I $\quad \mathbf{N} \quad \mathbf{F} \quad \mathbf{O}$}

\author{
Corresponding Author: \\ Khushboo Dewan, Department of Pathology, \\ Dr. Baba Saheb Ambedkar Medical College and \\ Hospital, Delhi, Rohini, Delhi, India. \\ E-mail Id: \\ khushboodewan@gmail.com \\ Orcid Id: \\ https://orcid.org/0000-0002-9685-9367 \\ How to cite this article: \\ Rani P, Dewan K, Khatri A, Patiri K, Mandal AK. \\ Occult Expression of Non Syndromic Sex Cord \\ Tumor with Annular Tubules in Ovary with \\ Coexistent Cervical Fibroid. Rec Adv Path Lab \\ Med 2020; 6(1\&2): 1-4.
}

Date of Submission: 2020-04-21

Date of Acceptance: 2020-07-23

\section{$\begin{array}{llllllll}\mathbf{A} & \mathbf{B} & \mathbf{S} & \mathbf{T} & \mathbf{R} & \mathbf{A} & \mathbf{C} & \mathbf{T}\end{array}$}

Sex Cord Tumor with Annular Tubules (SCTAT) is a rare ovarian tumor. It has morphological features intermediate between that of granulosa cell and sertoli cell. It is considered an estrogen and progesterone secreting tumor carrying low malignant potential. Due to its rare occurrence, its clinical recognition is difficult; hence, there are no standard treatment protocols. We present an incidentally detected SCTAT in the ovary coexisting with cervical fibroid.

Keywords: Sex Cord Tumor with Annular Tubules, Peutz Jeghers Syndrome, Cervical Fibroid

\section{Introduction}

The entity SCTAT was first described by Scully in $1970 .{ }^{1}$ It is an unusual distinctive variant of ovarian tumors accounting for $<1 \%$ of sex cord stromal tumors as per recent WHO classification of ovarian tumors. ${ }^{2}$ Sex cord stromal tumors are mainly divided into pure sex cord tumors, pure stromal tumors and mixed tumors. SCTAT comes under pure sex cord tumors along with granulosa and sertoli cell tumors. These are tumors of low malignant potential. It occurs in reproductive age group though rare pediatric cases have also been reported. ${ }^{3}$ Majority of cases are sporadic while one-third cases were found to be associated with PeutzJegher syndrome. Syndromic SCTAT occur at relatively young age (average 27 years) and usually are small $(<3 \mathrm{~cm})$, bilateral and mostly benign; however, one case of malignant SCTAT has been reported. ${ }^{2,4}$ Sporadic cases are large, unilateral, present at average age of 36 years and around one fifth cases show malignant transformation. ${ }^{2}$

Here, we are presenting a case of incidentally detected SCTAT of ovary in a 40 year old female without any association with Peutz-Jegher syndrome.

\section{Case Report}

A 40 year old female with parity 3, live birth 3, presented with progressively increasing pelvic pain and heavy menstrual bleeding for one year. Her menstrual cycle was regular, 8-9 days long, heavy and required pad changes 
every 4-5 hour on the heaviest days. Patient was severely anemic (Hb-4 gm\%) at the time of presentation for which she was transfused one unit whole blood , 4 units packed cells and 6 units fresh frozen plasma. Per vaginal examination revealed a 16 week sized anteverted uterus. Per speculum examination revealed a large mass protruding in the vagina occupying whole cavity, cervical os was not seen. Possibility of cervical fibroid/ cervical polyp was entertained. Preoperative imaging demonstrated grossly enlarged uterus with presence of a mass measuring $15.9 \times 9.1 \times 8 \mathrm{~cm}$ in lower uterine segment extending into cervical canal. Endometrial thickness was $6.2 \mathrm{~mm}$. Possibility of ?cervical? endometrial fibroid was given. Her family was complete, hence, was selected for definitive surgical management via hysterectomy. Total abdominal hysterectomy with bilateral salpingo-oopherectomy was done and tissue sample was sent for histopathological examination.
Gross examination revealed a distorted specimen of uterus cervix with attached bilateral adnexa measuring $13 \times 8 \times$ $5 \mathrm{~cm}$. Cervix was completely distorted and measured 6 $\mathrm{cm}$ long. Endometrial thickness was $0.4 \mathrm{~cm}$. Myometrium showed tiny adenomyotic foci. A globular grey white firm mass was lying separately in the container measuring $15 \mathrm{x}$ $11 \times 10 \mathrm{~cm}$. Right ovary measured $4 \times 3 \times 2 \mathrm{~cm}$, cut section showed tiny follicular cysts. Both the fallopian tubes and left ovary were unremarkable.

Microscopic examination of uterus cervix revealed mild chronic cervicitis, secretory endometrium and foci of adenomyosis. There was no glandular atrophy or decidualization. Thorough examination of cervix did not reveal any evidence of adenoma malignum. Sections from separately lying globular tissue showed features consistent with leiomyoma.

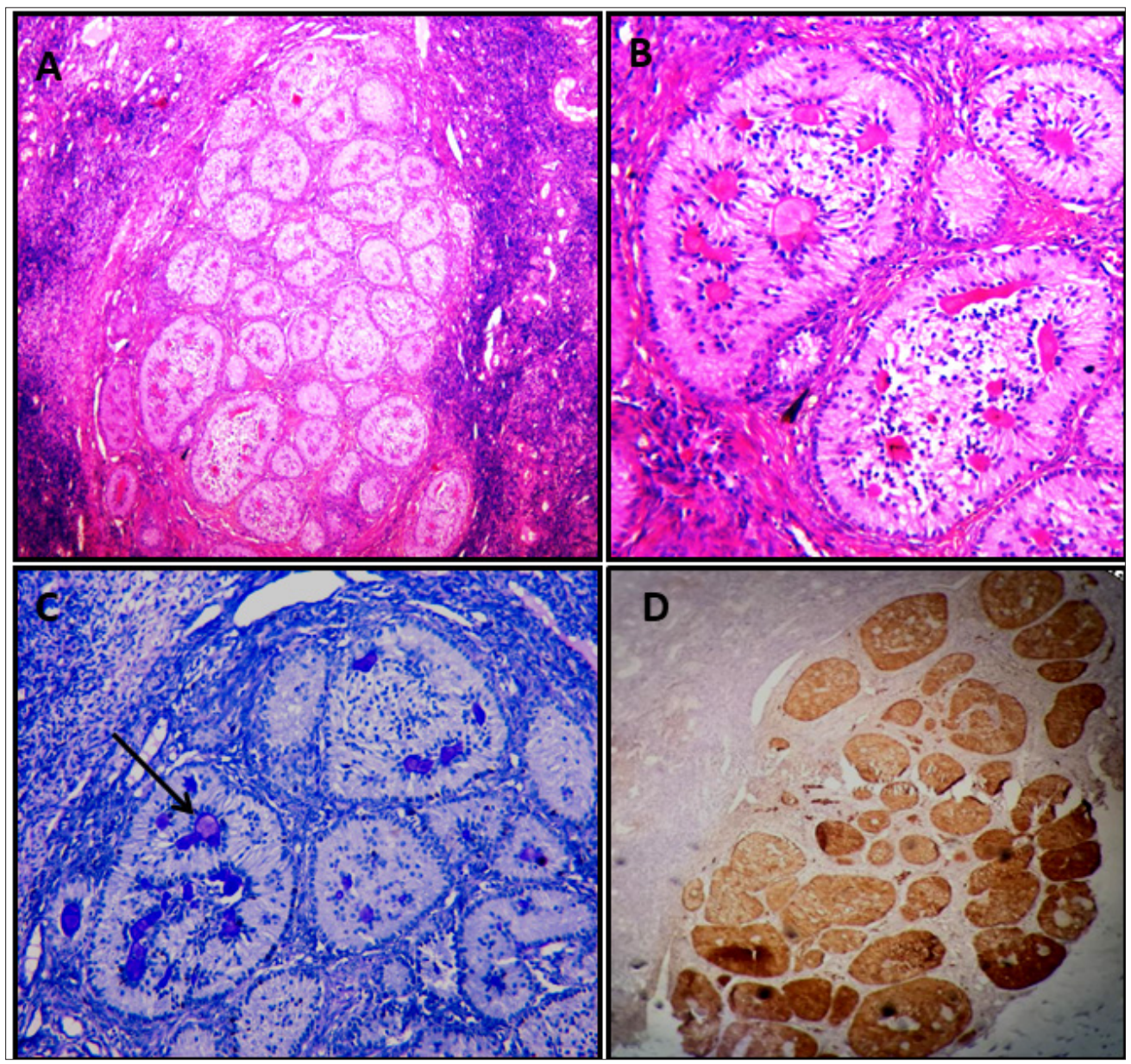

Figure I

(A): A focus of well circumscribed nests of epithelial cells composed of simple and complex annular tubules with central eosinophilc hyaline material. H\&E, 40X.

(B): Numerous complex annular tubules reveal communicating tubules encircling hyaline masses. The nuclei are arrayed in antipodal manner at the periphery of nest and around hyaline material. H\&E, 400X.

(C): The hyaline material of annular tubules showed positivity with Periodic Acid Schiff stain. 400X.

(D): The nest of annular tubular epithelial cells demonstrate cytoplasmic immunoexpression with Inhibin.40X. 
Sections examined from right ovary showed predominantly unremarkable ovary with a microscopic single well circumscribed grey white focus near the periphery of ovarian tissue. Microscopy revealed a nodular aggregate of tumor cells forming complex tubular structures enclosing eosinophilic hyaline material (Figures 1A, 1B). This eosinophilic material was PAS positive (Figure $1 \mathrm{C}$ ). The lining cells of tubules showed clear cytoplasm and antipodal arrangement of nuclei. No calcification, mitosis or atypia could be identified. Surrounding ovarian stroma was within normal limits. The tubular cells were positive for Inhibin (Figure 1D). Thus, a diagnosis of sex cord tumor with annular tubules (SCTAT) involving right ovary along with cervical fibroid was made. Patient was examined again to look for muco-cutaneous pigmentation and gastrointestinal endoscopy was done to search for polyps. However, there was no evidence of Peutz jegher syndrome.

\section{Discussion}

Sex cord tumor with annular tubules is a rare ( $<1 \%)$ subtype of ovarian sex cord stromal tumors. These tumors show morphological features intermediate between sertoli cell tumors and granulosa cell tumors. Few cases show CharcotBottcher filaments on electron microscopy suggesting sertoli cell origin while others don't show. It suggested that sporadic cases of SCTAT are of sex cord origin while syndromic cases are hamartomatous. ${ }^{5}$ Our case belonged to sporadic category as the patient did not reveal any features suggestive of Peutz Jegher syndrome. These tumors express Inhibin which is a protein secreted by sertoli cells (in males) and granulosa cells (in females) supporting their origin from sex cord. The clinical features of SCTAT are mainly because of estrogen and progesterone secretion such as precocious puberty, menorrhagia followed by persistent amenorrhea, post-menopausal bleeding or pelvic mass. These tumors secrete estrogen and progesterone which leads to decidual change of endometrial stroma along with glandular atrophy. ${ }^{6}$ Hence, in patients with ovarian tumor, who present with menorrhagia followed by amenorrhea, endometrial sampling should be done to look for these changes and possibility of SCTAT should be ruled out by simultaneous steroid hormone assay. The elevation of both estradiol and progesterone hormone with normal testosterone levels suggest the possibility of SCTAT while raised levels of all three hormones favour sertoli-leydig cell tumor. Apart from Peutz Jegher syndrome, SCTAT also show association with adenoma malignum of cervix, Turners syndrome, dysgerminoma, gonadoblastoma, endometrial carcinoma or endometriosis of fallopian tube. ${ }^{7-}$

${ }^{10}$ Hence, in a case of syndromic SCTAT cervical cancer, screening should be done to exclude adenoma malignum. Morphologically, these tumors present as solid, solid cystic or rarely cystic ovarian mass. Grossly, tan to yellow in colour with focal calcification. Syndromic SCTAT cases usually show calcification. ${ }^{2}$ Microscopically, classical cases demonstrate well circumscribed nests of epithelial cells composed of simple or complex annular tubules with central eosinophilc hyaline material which show bright PAS positivity. These tubules show antipodal arrangement of nuclei. In patients with Peutz-Jegher syndrome, annular tubules are usually seen scattered intermixed with normal ovarian tissue instead of distinct well circumscribed mass. ${ }^{2}$

SCTAT tumor cells express inhibin, calretinin, estrogen receptor, progesterone receptor, androgen receptor, CD10, FOXL 2, SF-1, WT-1 and CD56 on immunohistochemical analysis. In syndromic SCTAT cases mutation of STK11 results in loss of heterozygosity in the $19 \mathrm{p} 13.3$ region. This mutation is not detected in sporadic SCTAT. Around $20 \%$ of sporadic cases show low grade malignant course which metastasize via lymphatics as compared to direct extraovarian spread to peritoneum and omentum which is common in other sex cord stromal tumors. ${ }^{2}$

Although prognosis of this tumor is favourable, recurrence rate is high in these cases. Due to scanty literature regarding management of these tumors, there is no standard treatment protocol. A school of thought suggests that primary ovarian SCTAT with intact capsule can be treated with unilateral salpingo-oopherectomy with attempt to preserve fertility (if possible). In PJ syndrome bilateral ovarian involvement is seen. In this scenario, wedge section or biopsy from contralateral ovary may be considered though it is not a routine procedure. In patients with recurrence, complete recurrent tumor resection is done with long term follow up. ${ }^{11}$ In sporadic cases long term follow up along with serum inhibin levels and steroid assay is mandatory due to their possible malignant transformation. Annual surveillance with or without ultrasonography for 8-10 years is recommended.

\section{Conclusion}

In the present study, microscopic focus of ovarian SCTAT was detected incidentally in normal sized ovary in a case operated for cervical fibroid. As we know, sporadic cases of SCTAT have a risk of malignant transformation hence in a case of SCTAT meticulous histopathological sectioning should be done and the patient should be screened for PJ syndrome. This case did not show any evidence of PJ syndrome or malignancy. Cervix should also be screened carefully for possibility of adenoma malignum in syndromic cases.

\section{Acknowledgment}

We would like to thank all the authors \& all staff members of the Department of Pathology, Dr. BSAMCH, Rohini, Delhi for their support \& encouragement to prepare this report. The authors declare that there is no conflict of interest.

Conflicts of Interest: None 


\section{References}

1. Scully RE. Sex cord tumor with annular tubules a distinctive ovarian tumor of the Peutz-Jeghers syndrome. Cancer 1970; 25(5): 1107-1121.

2. Tavassoli FA, Devilee P. World health organization classification of tumors of female reproductive organs. Lyon: IARC Press; 2014

3. Nosov V, Park S, Rao J, Memarzadeh S. Non-PeutzJeghers syndrome associated ovarian sex cord tumor with annular tubules: a case report. Fertility and Sterility 2009; 92(4): 1497.e5-e8.

4. Lele SM, Sawh RN, Zaharopoulos P, Adesokan A, Smith $M$ et al. Malignant ovarian sex cord stromal tumor with annular tubules in a patient with Peutz - Jeghers syndrome: a case report. Mod Pathol 2000; 13(4): 466-470.

5. Kalifat R., de Brux J. Ovarian sex cord tumor with annular tubules: an ultrastructural study. International Journal of Gynecological Pathology 1987; 6(4): 380-388.

6. Young RH, Welch WR, Dickerson GR, Scully RE. Ovarian sex cord tumor with annular tubules: Review of 74 cases Including 27 with P-J syndrome and four with adenoma malignum of cervix. Cancer 1982; 50: 1384-1402.

7. Moon WS, Lee DG. Ovarian sex cord tumor with annular tubules in a patient with Turner syndrome. Journal of Korean Medical Science 1998; 13(1): 89-94.

8. Young KMN, Scurry J, Jaaback K, Bowden NA, Scott RJ. Bilateral dysgerminoma associated with gonadoblastoma and sex-cord stromal tumour with annular tubules in a 28-year-old fertile woman with normal karyotype. Pathology 2012; 44(3): 257-260.

9. Kondi-Pafiti A, Bakalianou K, lavazzo C, Dastamani C, Hasiakos D, Liapis A. Endometrial carcinoma and ovarian sex cord tumor with annular tubules in a patient with history of Peutz-Jeghers syndrome and multiple malignancies. European Journal of Gynaecological Oncology 2011; 32(4): 452-454.

10. Griffith LM, Carcangiu ML. Sex cord tumor with annular tubules associated with endometriosis of the fallopian tube. American Journal of Clinical Pathology 1991; 96(2): 259-262.

11. Qian Q, You Y, Yang J, Cao D, Zhu Z, Wu M et al. Management and prognosis of patients with ovarian sex cord tumor with annular tubules: a retrospective study. BMC Cancer 2015; 15: 270. 